\title{
Proposal and Development of a High Voltage Variable Frequency Alternating Current Power System for Hybrid Electric Aircraft
}

\author{
David J. Sadey ${ }^{1}$, Linda M. Taylor ${ }^{2}$, and Raymond F. Beach ${ }^{3}$ \\ NASA Glenn Research Center, Cleveland, $\mathrm{OH}, 44135$
}

\begin{abstract}
The development of ultra-efficient commercial vehicles and the transition to low-carbon emission propulsion are seen as strategic thrust paths within NASA Aeronautics. A critical enabler to these paths comes in the form of hybrid electric propulsion systems. For megawattclass systems, the best power system topology for these hybrid electric propulsion systems is debatable. Current proposals within NASA and the Aero community suggest using a combination of alternating current (AC) and direct current (DC) for power generation, transmission, and distribution. This paper proposes an alternative to the current thought model through the use of a primarily high voltage $\mathrm{AC}$ power system, supported by the Convergent Aeronautics Solutions (CAS) Project. This system relies heavily on the use of doubly-fed induction machines (DFIMs), which provide high power densities, minimal power conversion, and variable speed operation. The paper presents background on the activity along with the system architecture, development status, and preliminary results.
\end{abstract}

\section{Nomenclature}

$\begin{array}{ll}f_{\text {stator }} & =\text { stator frequency, hertz }(\mathrm{Hz}) \\ f_{\text {rotor }} & =\text { electrical rotor frequency, } \mathrm{Hz} \\ p & =\text { number of poles } \\ n_{\text {rotor }} & =\text { rotor speed, revolutions per minute }(\mathrm{rpm})\end{array}$

\section{Introduction}

$\mathrm{T}$ he NASA Aeronautics Research Mission Directorate (ARMD) is working to advance the state of future aviation. ARMD seeks to leverage advancements in existing technologies and standards to develop revolutionary solutions for future aviation challenges. One key area of development is an electrically driven system which would allow for the use of distributed propulsion. This distributed propulsion has the potential to enhance aircraft performance while improving overall energy efficiency and reducing $\mathrm{CO}_{2}$ emissions, as described by recent Research and Technology for Aerospace Systems (RTAPS) final reports ${ }^{1,2}$.

Two approaches to distributed electric propulsion are being investigated by ARMD. The first is a simplified baseline DC architecture investigated under an Advanced Air Transport Technology (AATT) project, as shown in Figure 1. This architecture consists of converting multi-phase AC power provided by a generator to DC power for transmission and distribution purposes across the network. The DC power is then converted to AC once again to drive the propulsor motors on the load end. Unfortunately, this topology requires that the AC-DC converter and sum of the DC-AC inverters on the distribution end each be sized for at least the full rated power of the generator. This results in a relatively large power electronics and switchgear mass on the aircraft, along with the requirement for a large amount of thermal mass to dissipate the heat within said power electronics and switchgear in the case of a non-cryogenic system.

\footnotetext{
${ }^{1}$ Electrical Engineer, Power Systems Division, 21000 Brookpark Rd./301-5, Non-Member.

${ }^{2}$ Electrical Engineer, Power Systems Division, 21000 Brookpark Rd./301-5, Non-Member.

${ }^{3}$ Senior Electrical Engineer, Power Systems Division, 21000 Brookpark Rd./301-5, Non-Member.
} 


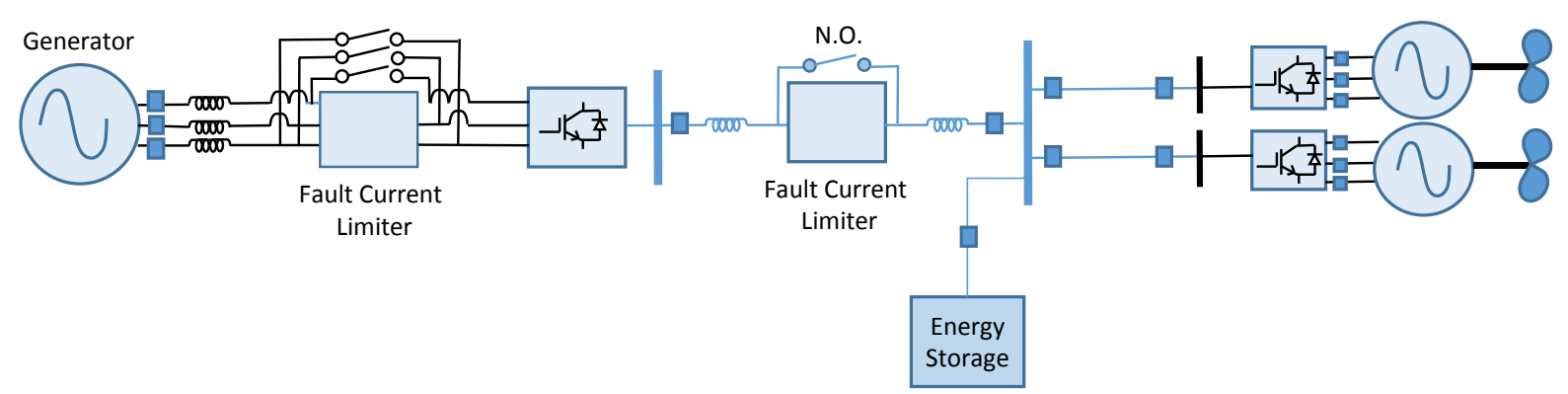

Figure 1. Simplified Baseline Architecture for Aircraft Power Generation and Distribution System²

The second approach is an AC system under development through the ARMD/Transformative Aeronautics Concepts Program's (TACP's) CAS High Voltage Hybrid Electric Propulsion (HVHEP) activity. This activity was formulated to support the ARMD's thrust into future hybrid electric aircraft, and low emissions goal through the development and feasibility demonstration of a new alternative to the aforementioned base architecture. The CAS HVHEP activity is proposing a high voltage, wide-range variable frequency, AC architecture for primary power transmission and distribution which can be seen in Figure 2. The move to this type of system results in many advantages. The most significant of these advantages being ease of voltage transformation, minimization of fault energy, and reduction in all around system weight. This proposed architecture will adopt the use of the DFIM for both generator (DFIG) and motor (DFI motor) use.

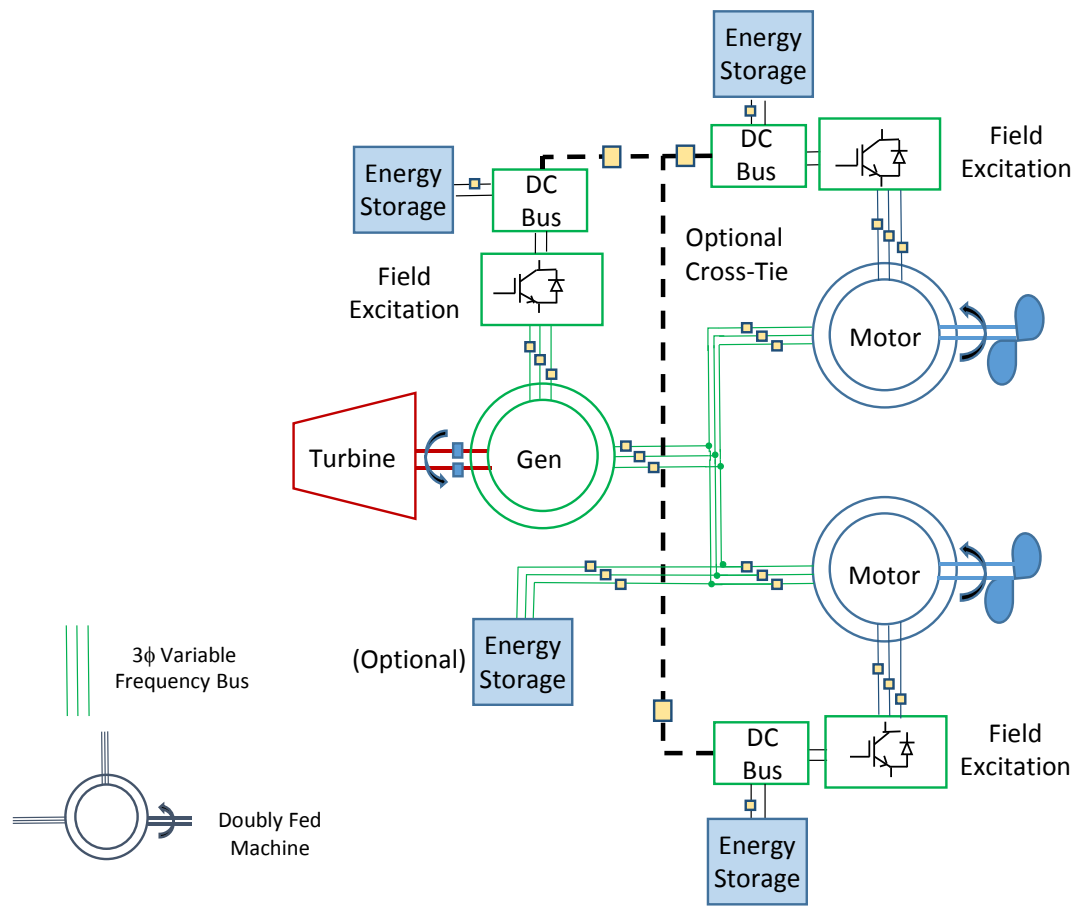

Figure 2. Proposed New Architecture Concept

Doubly fed machines are in common use in the wind turbine industry, and contain two active winding sets which contribute to the energy conversion process. Both windings contribute to electromechanical power production which allows the machines to operate over a wide range of frequency, speed, and/or torque. One of the primary advantages of the DFIM is that the power electronics are relegated to the rotor side. This is advantageous in the fact that the power electronics only have to be sized to process the slip power of the machine for speed, frequency, or torque control purposes. The slip power is the fraction of the air-gap power which is fed to or from the rotor electrically, and its magnitude (also a fraction of the rated machine power) is proportional to the actual rotor speed relative to the synchronous rotor speed. This will result in a reduction in overall power electronics (and in turn system weight) as compared to the simplified baseline DC architecture technology, which effectively increases aircraft efficiency and 
reduces $\mathrm{CO}_{2}$ emissions. This paper will describe this DFIM based AC power system, its control, potential benefits, challenges, and current development efforts to determine the validity of said system.

\section{Power System Architecture and Basic Principles}

Figure 2 is the conceptual power architecture for a potential DFIM based hybrid electric power system. The overall system consists of a DFIG, a primary AC transmission and distribution bus, several DFI motors to drive the propulsors, a DC bus which provides field excitation through an inverter, energy storage on the AC and DC buses, and breakers for protection.

\section{A. Generator}

The DFIG operates as a stand-alone generator acting as a voltage source, providing variable voltage, variable frequency power to the network. The capability to control output voltage and frequency allows the generator to essentially act as a variable speed drive to all downstream motor loads. As a variable speed drive, the DFIG can increase or decrease its output voltage and frequency proportional to one another to obtain higher or lower output power production respectively. In addition, the propulsor motors can be soft started, completely eliminating the need for full voltage starting for propulsor motors.

The control of the stator frequency is accomplished through field control by the inverter. When the inverter controls the rotor field such that it rotates in the same direction as the DFIG rotor, a super-synchronous bus frequency (high power operation) will result according to Eq. 1 , where $f_{\text {stator }}$ is the stator frequency, $n_{\text {rotor }}$ is the shaft speed in revolutions per minute $(\mathrm{rpm}), p$ is the number of poles of the machine, and $f_{\text {rotor }}$ is the electrical rotor frequency.

$$
f_{\text {stator }}=\frac{n_{\text {rotor }} * p}{120}+f_{\text {rotor }}
$$

Conversely, a rotating magnetic field controlled to rotate counter to the rotational direction of the DFIG rotor will create a sub-synchronous bus frequency (low power operation) according to Eq. 2.

$$
f_{\text {stator }}=\frac{n_{\text {rotor }} * p}{120}-f_{\text {rotor }}
$$

In both super- and sub-synchronous operating modes, the stator voltage is controlled by directly increasing or decreasing the field excitation voltage.

In terms of operating modes during the major stages of the flight profile, super-synchronous operation will be used in the takeoff and climb portions, along with maneuvering where higher output power is required for the aircraft. Subsynchronous operation on the other hand would be used during idling or descent where less power is required by the propulsor motors. Operation during cruise will most likely occur around the synchronous operating point.

\section{B. AC Transmission and Distribution Bus}

The voltage and frequency of the AC network are expected to be in the range of several kilovolts (kV) and kilohertz $(\mathrm{kHz})$ respectively. This allows for the distinct advantage of minimizing any possible magnetics, cabling, and switchgear on the transmission and distribution network, providing lower overall system weight. The high frequency AC transmission and distribution concept has been demonstrated and verified in past works at the $20 \mathrm{kHz}$ level at the NASA Glenn Research Center (GRC), including the development of low reactance cables for such a system ${ }^{3}$. It is important to note that no power processing exists on the AC bus; all power is directly transmitted from the generator to the motors. The electromagnetic interference (EMI) implications of this high frequency AC bus is a recognized concern however, and requires further study to identify the potential problems and possible solutions.

\section{DFI Motor}

The DFI motors operate under differential speed control to drive the propulsors and control thrust. In a manner similar to the DFIG and its output voltage and frequency, the DFI motors can control shaft speed sub- or supersynchronously relative to the stator frequency, independent of one another. This is performed via field control; excitation of the rotor via a three phase inverter tied to a DC bus allows control of the power flow to and from the rotor. Power injected into the rotor allows for super-synchronous operation of the DFI motor shaft, and power absorbed from the rotor allows for sub-synchronous operation. Field control of the DFI motor may also possibly allow several other unique advantages. One additional advantage is that through field control, any overhauling loads (loads pulling faster than the excited speed) that occur due to a drop in system frequency may have the ability to regenerate energy 
back through the rotor, not the stator, through ramped sub-synchronous operation. Secondly, if a DFI motor were to ever be isolated from the primary AC bus via the AC breakers opening, resynchronization to the AC bus can be accomplished by using field control to align the stator voltage with the grid voltage in phase, magnitude, and frequency, and then closing the AC breakers. The field could then be subsequently realigned to maximize the torque produced in the machine.

\section{DC Bus}

The DC bus, or DC buses in the case of a distributed architecture, plays a critical role in the proposed doubly-fed system. This bus is of the utmost importance, since the rotor power of each individual DFIM must be supplied to, or received from the DC bus itself through the respective DFIM inverters. To maintain stability throughout the system, the DC bus is expected to be regulated. Regulation will be accomplished through the use of energy storage elements and integral shunt regulators, which will maintain the voltage magnitude of the bus at the necessary set point and increase stability of the system.

A major benefit of the proposed system topology is that it offers multiple options for configuration of the DC bus or busses. This includes a common DC bus architecture, or distributed DC bus architecture. A common DC bus architecture would utilize cross-tying of distributed DC buses across the aircraft, and could occur solely on the motor side, or include the generator as well. If the DC bus associated with the DFIG was to be tied with the DC bus of the DFI motors however, the machines would be required to have equivalent stator-to-rotor turns ratios. On the other hand, a distributed DC architecture could be implemented, where each DFIM has its own respective DC bus. A distributed architecture would promote redundancy and increase reliability, while a common DC bus architecture would promote regenerative power flow to and from machines (at certain operating points) and the reduction of energy storage components.

\section{E. Load Leveling and Reactive Power Compensation}

The power and stability requirements of the aircraft power system over the flight profile may require additional power capability beyond that which the turbine was originally designed to provide. Peak demands during takeoff and maneuvers, and loss of load during descent can be partially supplied through the use of energy storage devices as load levelers. These energy storage devices can be incorporated on the DC bus via a variety of technologies such as capacitors, batteries and/or fuel cells interfaced through a bidirectional converter, and possibly the AC bus via an additional DFIM coupled to a flywheel ${ }^{4}$. The amount of energy storage and the storage medium have not been determined at this point in time, but it is important to note that all types of energy storage can easily be integrated into the system architecture.

\section{F. Protection}

The proposed system will be inherently reliable through a combination of AC and DC side protection via breakers, and also inverter field control. Similar to a common strategy used within terrestrial protection systems, the overall protection strategy for the doubly-fed system will analyze and clear faults based on a zone-based protection scheme. Simply, the system will be divided up into a number of protection zones, and it is the primary responsibility of the switchgear within the zone of the fault to clear said fault. One example is a fault on the AC bus. A bus differential relay would be responsible for clearing the fault by opening up all the breakers associated with the bus zone. Another example is a fault on the stator or rotor feeder conductors of a DFI motor. In this case, both the DC bus and the AC bus would contribute energy to the fault. Therefore, both the AC and DC buses would need to be isolated from the fault through breakers on each bus. During the fault, the DFI motor inverter is also expected to ramp down field excitation and disable operation. If the fault is cleared, the stator side breaker will remain open, and the DFI will resynchronize with the primary AC bus voltage, frequency, and phase, and slowly resume operation. One problem that must be addressed for the entire protection system, however, is that all faults must be cleared at high speed within the high frequency network so as to maintain system stability ${ }^{5}$.

\section{Power System Control}

In order for the proposed power system to effectively meet the demands of the pilot, and ensure safe and efficient operation of the aircraft, the power system must include both elemental and system-wide control. The control structure that meets such objectives is shown in Figure 3. In this structure, an overall power system controller monitors, configures, and issues set points to the individual power element controllers. The power element controllers directly control their respective individual power elements such as the DFIG, DFI motor, energy storage devices, and 
protective devices. The following is a breakdown of the high-level functions of each of the controllers shown in Figure 3.

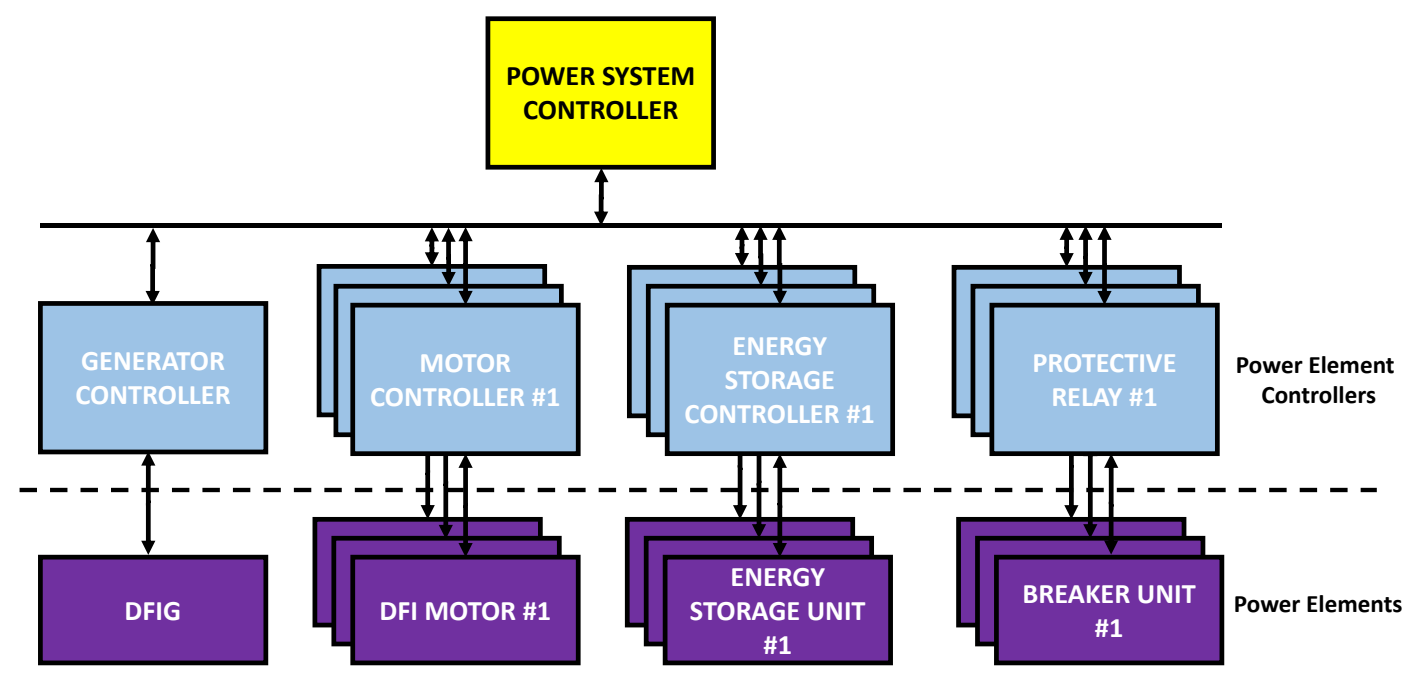

Figure 3. Power System Control Overview

\section{A. Power System Controller}

The power system controller is responsible for the overall power management function of the system. This includes configuring the system and issuing set points to the power system element controllers in such a way that the demands of the aircraft and the pilot are met in the safest and most efficient manner possible. For example, during the descent phase where the pilot pulls back on the throttle, the power system controller would monitor the system and issue set point commands for the controllers of the generator to ramp down voltage/frequency, of the DFI motors to ramp down on speed, and of the energy storage devices to capture regenerated power. These commands would be issued in such a manner that the system remain stable on the tail end of the flight profile. In addition, the power system controller would also be responsible for monitoring the system for any faults or potential issues, and given the event that a fault or an issue occurs, reconfigure the system and reroute the power such that aircraft has enough thrust to safely operate.

\section{B. Generator Controller}

The DFIG controller is issued voltage and frequency set points from the overall power system controller and must regulate the AC bus accordingly. The generator controller directly controls the DFIG through its inverter, based on the set points and feedback variables such as magnitude, frequency, and phase of the stator/bus voltage and rotor currents. Stand-alone DFIG operation and control has been demonstrated previously for fixed frequency $60 \mathrm{~Hz}$ operation for terrestrial application ${ }^{6}$; a form of this control strategy will be extended to regulate voltage and frequency over a wide range based on the demands of the aircraft power system. An adaptable and/or robust controller is expected to be necessary to ensure stability of this system, since the dynamics of the system will change with frequency.

\section{Motor Controllers}

The DFI motor controller inverters are issued speed set points from the overall power system controller and must regulate the propulsor shaft accordingly. The DFI motor controllers directly control their respective DFI motor and inverter pair based on the speed set point and feedback variables such as the stator/bus voltage and rotor currents. Speed control of individual DFI motors has been demonstrated for a fixed $60 \mathrm{~Hz}$ stator input in terrestrial application ${ }^{7}$; a form of this control strategy will be extended to a variable control solution, with a controller that retains stability of the individual DFI motors at all stator frequencies (which are provided by the DFIG) at sub- and super-synchronous operation.

\section{Energy Storage Unit Controllers}

The energy storage units controllers are issued active and or reactive power demand set points from the overall power system controller. The units must provide power to the system or store energy as necessary to ensure stability 
of the system. The units must also be monitored such that the total energy stored does not exceed or fall short of any predetermined threshold.

\section{E. Protective Device Relays}

Local high speed protective relaying will be associated with each breaker on the AC or DC bus to issue trip commands, similar to a utility system. The relays will communicate status updates with the overall power system controller, and can be commanded by the power system controller to open or close their respective breakers as well for power system configuration management.

\section{Preliminary DFIM System Development and Verification}

To develop, evaluate, and verify the operation of the proposed DFIM system, it is necessary to run the control against a representative power system; however, the cost and time necessary to perform these tasks on a high voltage and high frequency system are not attractive to NASA. The basic functionality of the system is being demonstrated using commercial off-the-shelf (COTS) low power hardware and simulation of such hardware to determine feasibility of the approach, and will be scaled to the megawatt (MW) level as the concepts are proven out. The existing low power test bed (LPTB) diagram and hardware is shown in Figures 4 and 5 respectively. The system currently consists of four 250 watt (W) permanent magnet DC (PMDC) machine and wound rotor induction machine (WRIM) pairs (the WRIM is a DFIM in this system), with the machines and AC bus configured in the same manner as the system shown in Figure 2. One pair simulates the DC machine as a turbine and the WRIM as a DFIG generator, while the other three pairs simulate the WRIM as a DFI motor and the DC machine as a fan load via dynamometer action. Each DFIM is fed via a three-phase inverter which ties to a nominal $42 \mathrm{~V}$ bus coupled to a regulated bidirectional DC supply. The LPTB uses the distributed DC architecture, where each machine has its own respective bidirectional DC bus (no cross tie). The test bed contains all of the necessary instrumentation for monitoring, control, and protection of the hardware, with all of the aforementioned functions being provided by a high-speed data acquisition and control system.

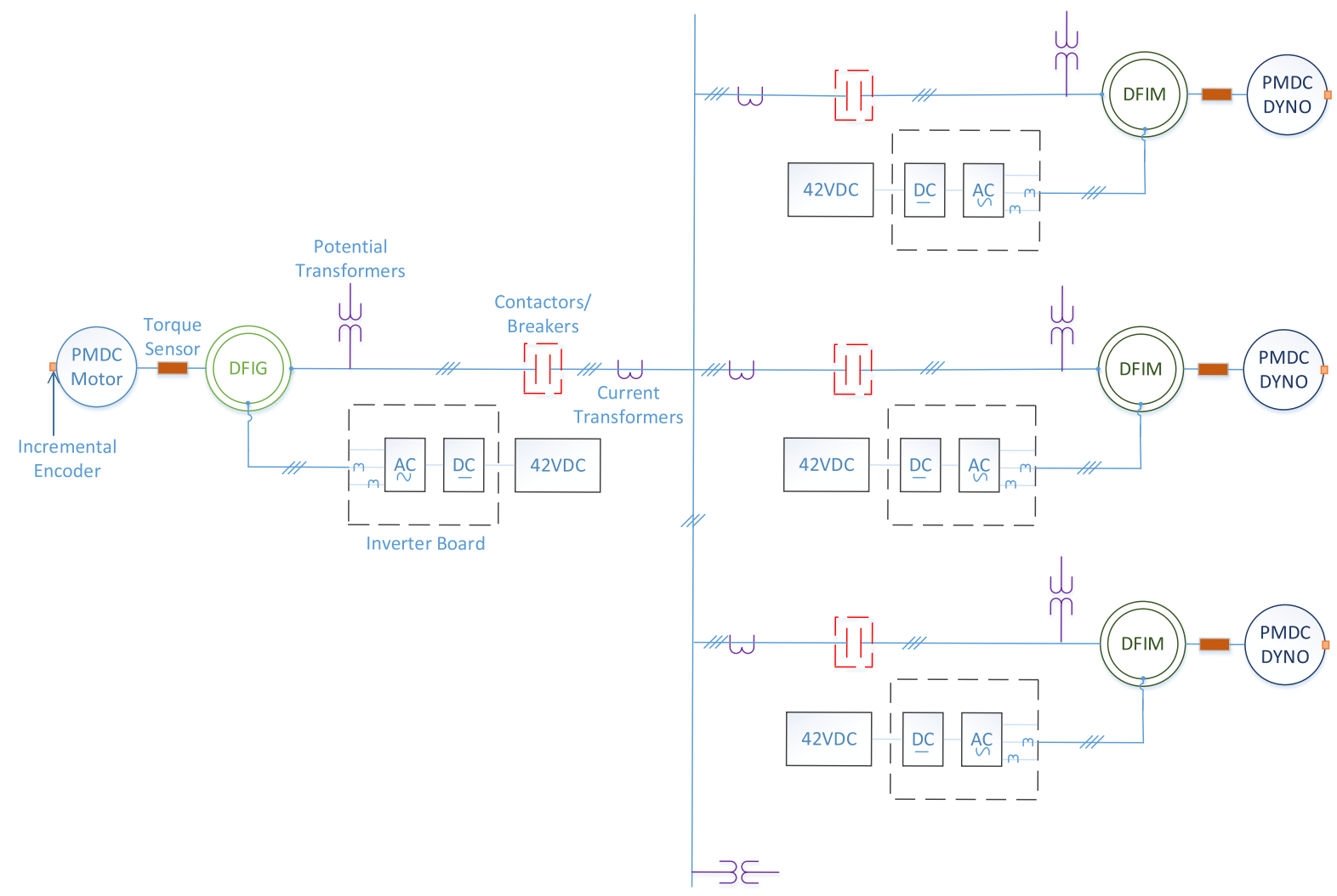

Figure 4. Low Power Test Bed Schematic 


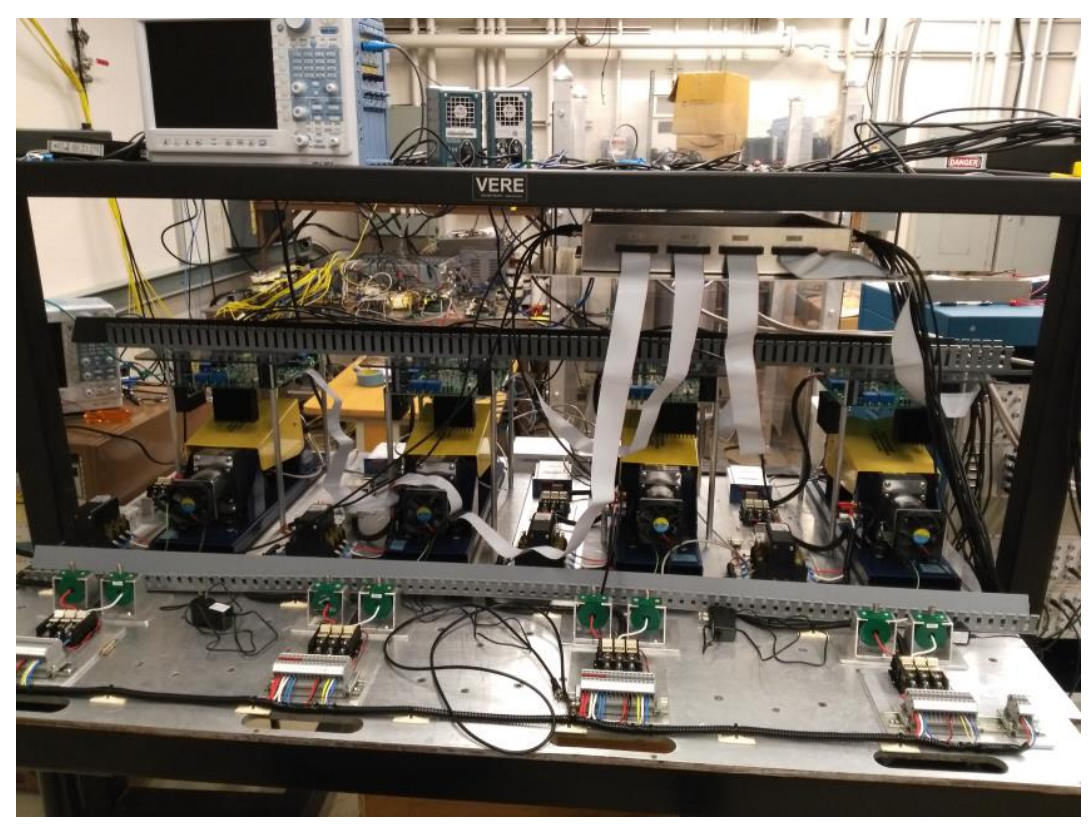

Figure 5. Low Power Test Bed Hardware

The LPTB machines have completed preliminary testing and evaluation, with the analytical models of the machines being developed using Simscape Power Systems ${ }^{\mathrm{TM}}$. The state-averaged model of the inverter based on the data sheet characteristics has also been developed within Simscape Power Systems ${ }^{\mathrm{TM}}$. A comparison of the simulation and hardware results are shown in Figures 6 and 7 for the WRIM with shorted rotor coupled to the DC Machine. Figure 6 shows the applied stator voltage of 15 volts root mean square (RMS) line-to-line at $60 \mathrm{~Hz}$ to the DFIM, and Figure 7 shows the resulting stator current. Rotor current simulation results were also found to be within 10 percent of the hardware values. Test results have shown good correlation between the software models and the hardware. However, the results have also demonstrated the inefficiencies of the fractional horsepower machines, especially the DFIG. These losses include relatively high leakage resistances due to small conductor sizes, and relatively high frictional losses compared to the rating of the machine. A $750 \mathrm{~W}$ alternative generator is currently being developed to overcome these inefficiencies and provide increased power system capacity to the existing motors.

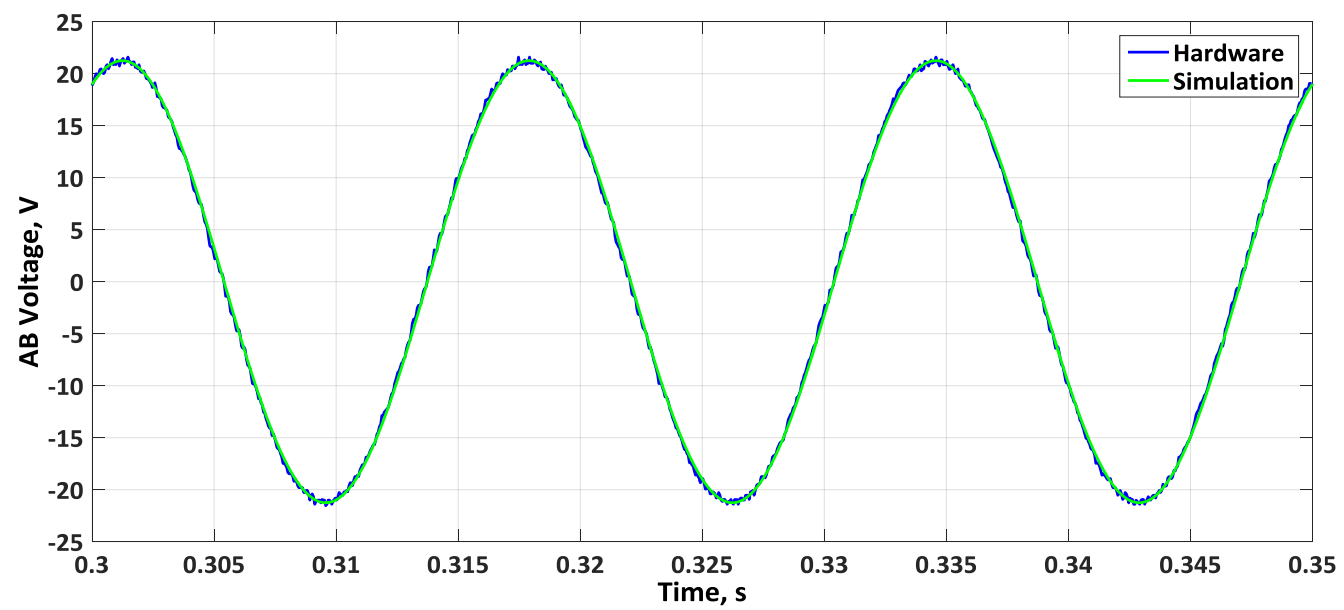

Figure 6. Applied Stator Line to Line Voltage AB to WRIM coupled to PMDC Machine, Hardware versus Simulation 


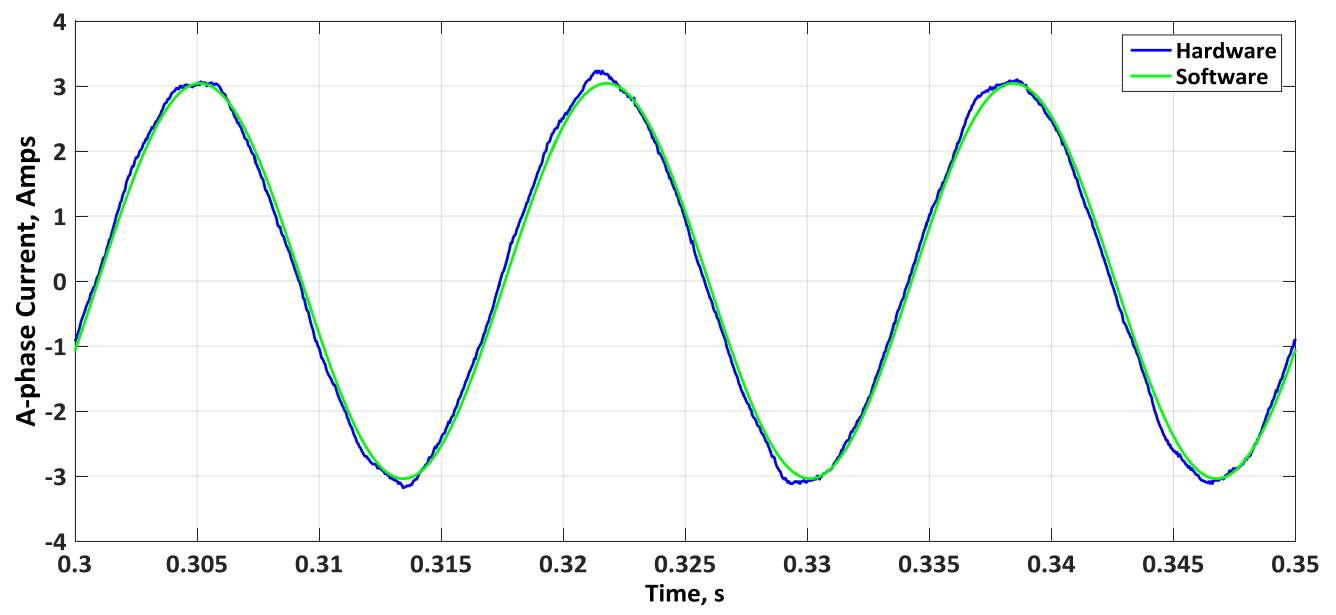

Figure 7. Stator Currents of WRIM coupled to PMDC Machine, Hardware versus Simulation

With accurate hardware models, the basic control and stability of the system will first be demonstrated in software. This consists of demonstrating the power element control layer containing the regulator loops for the DFIG and DFI motor, then integrating the power control elements together and adjusting the top level control system to guarantee stability of operation. Once the total control of the system and its elements are realized within the software environment, the controls will be directly applied to the test bed hardware using rapid prototyping technology. This provides development and evaluation in a timely and cost effective manner, with minimal risk to hardware.

A preliminary PI-based DFIG controller has recently been developed by NASA GRC to demonstrate closed-loop voltage and frequency control of the generator. This controller is based on the control techniques described for a standalone terrestrial DFIG in Ref. 6, and is interfaced with the stand-alone DFIG system shown in Figure 8. The generator contains the same characteristics as the $250 \mathrm{~W}$ machine described previously, has a constant shaft speed of $1800 \mathrm{rpm}$ and has its stator feeding a fixed wye-connected load with $5 \mathrm{Ohms}$ and $10 \mathrm{uF}$ per phase. Variable frequency and voltage operation is demonstrated in Simscape Power Systems ${ }^{\mathrm{TM}}$ as shown in Figure 9, which shows the primary bus voltage and frequency shift from sub-synchronous operation at 12.75 volts RMS line-to-line and $51 \mathrm{~Hz}$ respectively, to supersynchronous operation at 17.5 volts RMS line-to-line and $69 \mathrm{~Hz}$ respectively.

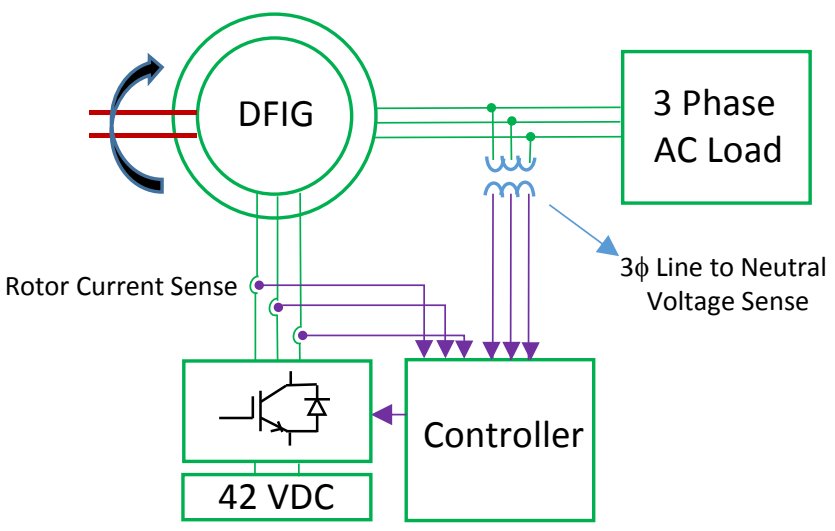

Figure 8. Stand-Alone DFIG System Implemented in Simulation 


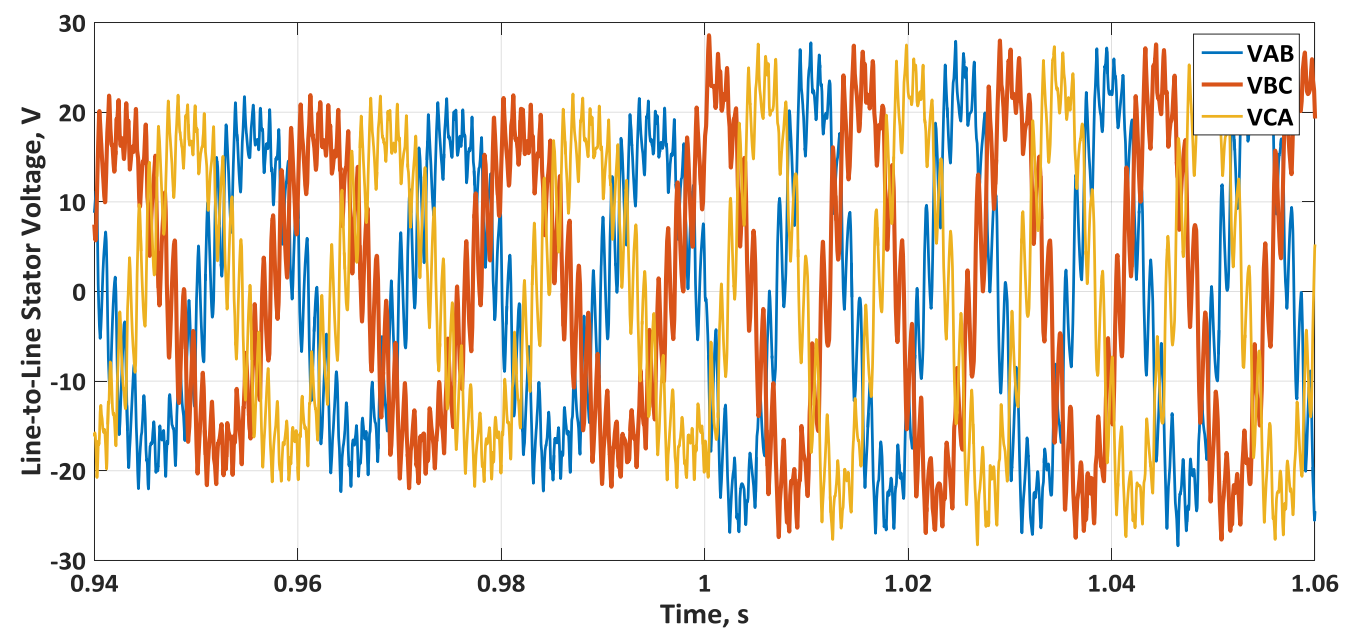

Figure 9: Simulation Demonstration of Variable Stator Voltage and Frequency

Robustness and stability of the overall control strategy will be evaluated in the future with respect to various operating voltages and frequencies on the bus with dynamic loads. In addition to the DFIG control, a variation of the speed control algorithm of the DFI motor demonstrated in Ref. 7 is being evaluated, along with the possible inclusion of a DFIM based AC energy storage system.

\section{Summary and Future Work}

Hybrid electric vehicles may enable development of ultra-efficient commercial vehicles and the transition to lowcarbon emission propulsion, which are critical thrust paths within NASA. NASA GRC has proposed a primarily AC based power system architecture which reduces cable, power electronics, and switchgear weight through the use of high voltage, high frequency, doubly-fed machines. Prior work based on $60 \mathrm{~Hz}$ operation of the DFIG and DFI motor has been demonstrated in academia, and these concepts will be expanded to variable operation. The challenges of implementing and integrating such a system are currently being investigated through the use of a low power test bed. If stable operation of the proposed system is verified, NASA GRC plans to expand demonstration on a high power test bed, possibly in the MW range.

\section{Acknowledgments}

The authors would like to thank the NASA CAS project for the support of this effort, Benji Loop and Ning Wu of PC Krause and Associates who assisted with the simulation results, and Casey Theman, Keith Hunker, Tom Balogas, David Hausser, and George Horning of the CAS HVHEP activity for their assistance in the construction of the low power test bed.

\section{References}

${ }^{1}$ Gemin, P., et al., RTAPS “Architecture, voltage and components for a turboelectric distributed propulsion electric grid (AVCTeDP),” NASA CR-2015-218713, 2015.

${ }^{2}$ Armstrong, M.J., et al., RTAPS “Architecture, Voltage, and Components for a Turboelectric Distributed Propulsion Electric Grid,” NASA CR-2015-218440, 2015.

${ }^{3}$ Hansen, I. G., and Wolff, F. J., “20 kHz Space Station power system,” NASA TM-88801, 1986.

${ }^{4}$ Ferreira, A. C., Souza, L. M., and Watanabe, E. H., "Improving power quality with a variable speed synchronous condenser," Power Electronics, Machines and Drives, 2002. International Conference on (Conf. Publ. No. 487), 2002, pp. 456461

${ }^{5}$ Zheng, H., "High Frequency AC Power Systems," Ph.D. Dissertation, Electrical Engineering Dept., University of South Carolina, Columbia, S.C., 2014. 
${ }^{6}$ Iwanski, G., and Koczara, W., "Sensorless direct voltage control method for stand-alone slip-ring induction generator," Power Electronics and Applications, 2005 European Conference on, Dresden, 2005, pp. 10 pp.-P.10.

${ }^{7}$ Yuan, X., Chai, J., and Li, Y., “A Converter-Based Starting Method and Speed Control of Doubly Fed Induction Machine With Centrifugal Loads," IEEE Transactions on Industry Applications, vol. 47, no. 3, pp. 1409-1418, May-June 2011. 